\author{
Parents' Expectations for and Reactions to Children's Racial Biases \\ Katharine E. Scott, Kristin Shutts, \& Patricia G. Devine \\ University of Wisconsin-Madison
}

\begin{abstract}
Authors' notes:
Data, materials, and supplemental analyses for this project can be found at http://osf.io/uxndw/

Address correspondence to Katharine E. Scott (Email: kscott4@,wisc.edu)

We thank Rista C. Plate and Jellie Sierksma for comments on previous versions of this paper and Seth D. Pollak for his insight throughout the development and execution of these studies. We also thank Megan J. Kaul, Teagan N.

Twombly, and Nicole A. Huth for their help recruiting participants and creating the studies presented in this paper. Preparation of this article was supported by a University of Wisconsin-Madison Graduate School fellowship awarded to the first author, a Wisconsin Alumni Research Foundation Professorship awarded to the last author, a Menzies Research Award from the University of Wisconsin-Madison, and NIH grant 5R01GM111002-02. This study was supported in part by a core grant to the Waisman Center from the National Institute of Child Health and Human Development (U54 HD090256).
\end{abstract}




\begin{abstract}
How do parents think about and react to their children's racial biases? Across three studies $(N=$ 519) we investigated whether and how parents' internal motivation to respond without prejudice (IMS) predicted standards for their children's race-related behavior, and tested parents' affective reactions to imagining their children violating their standards. Studies 1 and 2 demonstrated that parents (of 4-12-year-old children) with high IMS set more stringent standards for their children's race-related behavior than their low IMS counterparts. Upon considering their children expressing racial bias, high IMS parents reported negative self-directed affect (i.e., guilt; Studies 2 and 3), an affective response that motivates prejudice reduction in adults. The results have implications for involving parents in prejudice interventions targeting children's biases. Keywords: Parenting, Racial Bias, Children, Prejudice
\end{abstract}




\section{Parents' Expectations for and Reactions to Children's Racial Biases}

Children display racial bias early in development, with prejudice peaking between 5 and 7 years of age (Aboud, 1988; Raabe \& Beelmann, 2011). Although children from various backgrounds display and are affected by racial bias, a prominent focus in the literature has been on the Black-White context. In the United States, White preschool and elementary school-age children prefer White children to Black children (Baron \& Banaji, 2006; Kowalski, 2003; Weisman, Johnson, \& Shutts, 2015), allocate more resources to White than to Black children (Renno \& Shutts, 2015), and attribute more negative traits to Black than to White people (Pauker, Ambady, \& Apfelbaum, 2010). Further, many minority elementary and middle school children recognize that they have been victims of discrimination (Brown \& Bigler, 2005). For example, in one study with Black 10-year-old children in the U.S., most participants reported having experienced racial discrimination from peers (Simons et al., 2002).

Such biases are troubling and have led some to suggest addressing racial biases in childhood before they are deeply entrenched (e.g., Rutland \& Killen, 2015). In particular, because of their role as key socialization agents, parents have been implicated as important agents for addressing children's biases (e.g., Pahlke, Bigler, \& Suizzo, 2012; Waxman, Richeson, \& Rogers, 2017). The suggestion to include parents in intervention efforts is reasonable given that parents' cognitive and affective reactions to children's behaviors shape children's understanding of right and wrong (Smetana, 1999). To date, however, little is known about what parents think about the acceptability of children's racial biases, let alone how they react when their children display racial biases.

In recent years, however, researchers have begun to explore how parents interact with their children around the topic of race. Multiple studies have shown that although White parents believe it is important to discuss race with their children, they tend to avoid race-related 
conversations (Pahlke et al., 2012; Vittrup, 2016; Vittrup \& Holden, 2010; Zucker \& Patterson, 2018). When White U.S. parents in one study were asked to have race-related discussions with their 5-7-year-old children, only $10 \%$ reported having in-depth conversations about the topic (Vittrup \& Holden, 2010). In another study conducted with White families in the U.S. (Pahlke et al., 2012), mothers were provided with books that had content relevant to intergroup relations and were asked to read and discuss the books with their children as they would at home. The majority of mothers never mentioned race throughout the course of the study session. Further, when asked, mothers estimated that their children would not show racial bias on a laboratory trait attribution measure. In reality, and in accordance with previous research, children did display racial bias on the task: they attributed more positive and fewer negative traits to White people than to Black people.

Although these studies provide insight into how White parents approach race, they leave open many questions about the standards that parents have for their children's race-related behavior, the influence of parents' values on their expectations for their children, and the nature of parents' reactions to children's biases. In a series of three studies evaluating these issues, the present research adapts a framework from the adult literature to the parent-child context.

\section{Values Framework}

Decades of research on intrapersonal self-regulation of prejudice in adults has evaluated why some people but not others prohibit personal expressions of prejudice, as well as how people react to their own expressions of prejudice (Amodio, Devine, \& Harmon-Jones, 2007;

Devine, Monteith, Zuwerink, \& Elliot, 1991; Plant \& Devine, 1998). People’s values regarding how to treat stigmatized others determine the standards they set for their own behavior in the prejudice domain (Plant \& Devine, 1998). Specifically, people who are high in Internal Motivation to Respond without Prejudice (IMS) have strongly internalized values that prohibit 
prejudice and set stringent standards precluding the expression of prejudice. In contrast, people who are low in IMS have less strongly internalized values regarding the acceptability of prejudice and set more lenient standards that permit greater bias in their behaviors. For example, people who are high in IMS are more likely than those low in IMS to indicate that they should not feel uncomfortable when a Black person sits next to them on a bus.

People's level of IMS also influences how they respond when they behave with more bias than they deem acceptable (Plant \& Devine, 1998). For people high in IMS, violations of standards lead to negative self-directed affect (i.e., guilt) and regulatory efforts to realign behaviors with their standards (Amodio et al., 2007; Monteith, 1993; Monteith, Ashburn-Nardo, Voils, \& Czopp, 2002). When people low in IMS behave with bias exceeding their standards, they neither experience guilt nor make efforts to realign their behavior with their standards.

Devine and colleagues have focused primarily on the intrapersonal domain, assessing affective and regulatory responses to personal transgressions of standards (but see Mitamura, Erickson, \& Devine, 2017). Extending the Values Framework to the interpersonal context of the parent-child dyad may hold promise for shedding light on how parents' values affect the standards they hold for their children, how parents expect their children to behave in the race domain, and how parents react to their children's transgressions.

\section{Study 1}

Study 1 applies the logic of the Values Framework to the parent-child context in order to explore parents' thinking about children's racial biases. To this end, we adapted an established method to assess parents' standards for their children's behavior, expectations for how their children would behave, and affective reactions to transgressions of standards. Following prior research showing that people set standards for both the self (e.g., Plant \& Devine, 1998) and unknown others (Mitamura et al., 2017) that reflect their levels of IMS, we anticipated that 
parents would set more stringent non-prejudiced standards for their children as parents increased in IMS (Hypothesis 1). We also measured parents' expectations for what their children would do in race-related situations and assessed affective consequences of mismatches between parents' standards and expectations for their children. Consistent with findings in the adult literature on personal reactions to violating standards, we anticipated that parents' affective reactions to children's violations would vary as a function of the parents' level of IMS. Specifically, we expected that when considering children's transgressions, high IMS parents would express negative self-directed affect more so than low IMS parents (Hypothesis 2).

The present study also affords an opportunity to explore the role of child age in parents' affective reactions to children violating their standards. Previous work suggests that as children age, parents view children as increasingly intentional actors (Dix, Ruble, Grusec, \& Nixon, 1986) and expect children to behave in increasingly appropriate ways (Walker \& Taylor, 1991). Thus, we reasoned that high IMS parents, who are expected to be concerned about violations of their standards, might feel elevated anger directed at the child in response to violations of their standards as their children got older (Hypothesis 3). Child-directed negative affect may replace, or occur in addition to, negative self-directed affect.

\section{Method}

Participants. Based on prior research using a similar paradigm (e.g., Plant \& Devine, 1998), we assumed a small to medium effect for our primary hypotheses $\left(f^{2}=.10\right)$. With this assumption, we conducted an a priori power analysis using a series of simulations in $\mathrm{R}$ that yielded a required sample size of 200 parents to detect an interaction of IMS and discrepancy magnitude. We ceased recruitment efforts when we obtained data from 200 parents; data were collected, however, from parents to whom surveys had already been distributed when we reached the predetermined sample size. 
Most parents were recruited from a database containing contact information for parents who expressed interest in research related to social development. We also recruited parents $(n=$ 34) though advertisements placed in local online parenting forums. Parents in this study and all subsequent studies had at least one child between the ages of 4 and 12 . Parents received a $\$ 10$ gift card for completing the study.

All parents in this study were from a city in the Upper Midwest region of the United States. Families with Asian, Hispanic, and White children were included because children from these groups have been shown to favor members of their own group over Black people (Aboud, 1988; Dunham, Baron, \& Banaji, 2007). Black parents and parents with an immediate family member who is Black were excluded from data analysis $(n=23)$ because asking parents to think about their children displaying bias against members of their own group is fundamentally different than asking them to reflect on displays of intergroup bias. Parents who had not lived in the United States at least 5 years were excluded $(n=3)$ because the study required an understanding of race relations in the United States.

The final sample ( $N=219 ; 195$ female, 22 male, 2 did not report $)$ included $84.93 \%$ White, $8.22 \%$ Asian, and 6.39\% Hispanic parents. Most $(n=200)$ parents were between 30 and 50 years old; 10 parents were under age 30 and 9 parents were older than age 50 . The median household income of the sample was between $\$ 90,000$ and $\$ 100,000$ per year. Parents' highest levels of education were as follows: $33.33 \%$ graduate degrees, $47.03 \%$ bachelor's degrees, $14.61 \%$ associate's degrees, $4.11 \%$ high school degrees, and $0.46 \%$ no high school degree.

Procedure and Design. Parents completed this study online on their own computers. If parents had more than one child between the ages of 4 and 12 years, parents were randomly assigned to think about a specific child $(M=6.88$ years, $S D=2.27$ years $)$. Measures in this study were presented in the order listed below. The order of the questions in each scale was 
randomized for each parent. Parents completed one final measure that served as pilot data for another study and will not be discussed further. The data for all three studies described in this manuscript were collected between April 2016 and June 2017. Measures, data, R codes, and supplemental analyses for all reported studies are available on OSF: https://osf.io/uxndw/.

Measures. Motivation to Respond Without Prejudice. Parents responded to Plant and Devine's (1998) Motivation to Respond Without Prejudice Scale. The scale consists of 5 items assessing internal motivation to respond without prejudice (IMS). IMS items assessed the extent to which being non-prejudiced was personally important to parents (e.g., "I am personally motivated by my beliefs to be nonprejudiced toward Black people"). Parents' responses could range from 1 (strongly disagree) to 7 (strongly agree). Parents also completed 5 items measuring external motivation to respond without prejudice (EMS). EMS was not central to our hypotheses and will not be discussed in the present paper. We note, however, that the inclusion of EMS in analyses does not alter the core findings; datasets including EMS items are available at https://osf.io/uxndw/.

Shoulds measure (See Appendix). The shoulds measure assessed parents'standards for their children's race-related behaviors. The shoulds measure was inspired by a measure used in the Values Framework for evaluating the standards people set for their own behavior in the prejudice domain (Devine et al., 1991). The content of the items was adapted to be appropriate for parents thinking about how their children should behave in the domain of prejudice. We generated 14 items, drawing from examples in news outlets (Slate, 2013), blog posts (Baby Center, 2016), and personal stories communicated to us by parents in our lab. [For example, a parent in a news article reported that her child made comments such as "I don't want to sit by him because he has dark skin" (Slate, 2013).] 
For each item, parents reported how they thought their children should behave in the described situation (e.g., "Your child should refuse to sit next to a Black person on the school bus."). Parents were asked to indicate the degree to which they agreed or disagreed with items on a 1 (strongly disagree) to 7 (strongly agree) Likert-type scale. Items were reverse coded when necessary such that higher ratings represented more prejudiced standards. A total "shoulds" score was formed by averaging parents' responses across the 14 items $(\alpha=0.75)$.

Woulds measure (See Appendix). Next, parents indicated how they expected their children would behave in the same 14 race-related situations from the previous measure (e.g., "Your child would refuse to sit next to a Black person on the school bus."). Again, parents used a Likert scale ranging from 1 (strongly disagree) to 7 (strongly agree). Seven items were reverse coded such that higher scores indicated more biased responses. A total "woulds" score was formed by averaging parents' responses across the 14 items $(\alpha=0.79)$.

Discrepancy index. A “discrepancy" score $(\alpha=0.59)$ was calculated by subtracting parents" "should" score from their "would" score on each item and averaging across items to represent the mismatch between how parents thought their children should and would behave. Positive scores indicated that parents believed children would express more prejudice than their standards allow. Discrepancies equal to zero indicated that parents thought their children would behave in accordance with their standards. Negative scores indicated that parents thought children would actually express less bias than they viewed as acceptable. Following established practices, we excluded negative discrepancy scores $(n=44)$ from analyses that included discrepancy scores, as the interpretation of negative discrepancies is ambiguous (Devine et al., 1991; Plant \& Devine, 1998).

Affect measure. After responding to the should and would items, parents indicated the degree to which each of 34 affective states (e.g., guilty, disappointed in my child, good) 
described their feelings about how well their standards for their children matched their expectations for their children (Devine et al., 1991; Plant \& Devine, 1998). Specifically, parents were provided with the following instructions:

Consider the above situations once again, but this time focus on your feelings about how well your expectations for how your child would respond in these situations match how you reported your child should respond. For each word below, please indicate how much it applies to your current feelings by circling a number on the scales. "1" means "does not apply at all", and "7" means "applies very much" to how you are currently feeling. Don't spend much time thinking about each word; just give a gut-level response.

\section{Results}

Overview of Analyses. In this study and all subsequent studies, analyses were conducted with general linear models (GLMs) in R. Predictor variables were centered and simultaneously regressed on the outcome variables as suggested by Judd, McClelland, and Ryan (2011). Dichotomous variables were recoded to -0.5 and 0.5 , and continuous variables were centered around the mean.

Descriptives. In previous work, the IMS, shoulds, woulds, and discrepancy measures have been validated with college students (Plant \& Devine, 1998). We examined a variety of descriptive statistics (Table 1) and correlations (Table 2) to evaluate the extent to which our sample characteristics resembled those used in previous work. Although the means and distributions of IMS and shoulds scores were highly consistent with prior research, the mean discrepancy score was very small and was substantially lower than in prior work (Plant \& Devine, 1998).

Construction of Affect Indices. To create the affect indices used in the studies, we conducted a factor analysis on the 34 affect items using data from participants in Studies 1 and 2 
(Study 3 parents were the same as in Study 1). We extracted three factors marked by eigenvalues over 1.00 using an oblimin rotation. Items that loaded onto one of the factors at .55 or higher were averaged together to create an index for parents on each factor. The three factors were negative self-directed affect ( $\alpha=0.97$; e.g., self-critical, guilty, angry at myself), negative childdirected affect ( $\alpha=0.95$; e.g., disappointed in my child, angry at my child), and positive affect ( $\alpha=0.90$; e.g., pleased with myself, good). The factors accounted for $39 \%, 15 \%$, and $11 \%$ of the variance, respectively, accounting for a total of $65 \%$ of the variance.

Shoulds and Woulds for Children's Behavior. Consistent with Hypothesis 1 and with previous research, IMS was associated with the standards (shoulds measure) parents set for their children such that parents who were higher in IMS set more stringent non-prejudiced standards for their children than those lower in IMS, $B=-0.24, S E=0.04, t(215)=-6.43, p<0.001, \Delta R^{2}=$ 0.16. Furthermore, we found a negative correlation between IMS and parents' ratings of what their children actually would do such that parents who were higher in IMS expected children to express less bias than did parents who were lower in IMS, $B=-0.28, S E=0.04, t(215)=-7.11, p$ $<0.001, \Delta R^{2}=0.19$. There were no significant effects of child age on parents' should or would ratings $(p s>0.05)$.

Affect Analyses. We regressed negative self-directed affect, negative child-directed affect, and positive affect, in turn, on IMS, discrepancy magnitude, child age, and all possible interactions. Results corresponding to each relevant hypothesis and other significant effects are reported below. See Table 3 for the summary of all effects in the full regression models.

The analysis of negative self-directed affect revealed a main effect of IMS on negative self-directed affect such that as parents increased in IMS they reported less negative self-directed affect $(p=0.008)$. Critically, there was no IMS X discrepancy magnitude interaction on parents' negative self-directed affect, failing to support Hypothesis $2(p=0.39)$. There was also a main 
effect of child age on negative self-directed affect $(p=0.01)$ : as children aged, parents reported less negative self-directed affect. Finally, there was a main effect of discrepancy magnitude such that as discrepancies increased, parents reported more negative self-directed affect $(p=.03)$. The analysis on positive affect revealed only a main effect of IMS on positive affect $(p=0.02)$ such that parents who were higher in IMS reported more positive affect. Next, we evaluated whether parents higher in IMS would express more negative child-directed affect when children violated their standards as children aged (Hypothesis 3). There was a main effect of IMS on negative child-directed affect such that parents who were higher in IMS reported less negative child-directed affect $(p=0.004)$. The three-way interaction of IMS, discrepancy magnitude, and child age was not significant $(p=0.76)$, failing to support Hypothesis 3 .

\section{Discussion}

The goals of Study 1 were to evaluate the standards parents set for their children in the race domain as a function of their level of internal motivation to respond without prejudice, to assess how parents think their children would behave, and to evaluate the affective consequences that follow when children transgress their parents' standards. As anticipated, and providing support for Hypothesis 1, parents set more stringent non-prejudiced standards for their children as parents increased in IMS. These findings provide a conceptual replication of prior research on the relation between IMS and standards set for the self (Plant \& Devine, 1998) and for unknown others (Mitamura et al., 2017). In contrast to previous work in which the overwhelming majority of adults expected that they would respond with more bias than their standards permitted (e.g., Plant \& Devine, 1998), parents in the present study generally did not anticipate their children's behavior to violate their standards. Although the items differed in severity, parents reported low discrepancies across the items (range: $0.01-0.34$; possible range: $0-7$ ). 
How should we interpret that parents reported their children would be unlikely to violate their standards? One possibility is that the results were specific to the sample in Study 1; the participants in Study 1 all lived in the same Upper Midwest city in the U.S., were relatively affluent, and were highly educated. To explore this possibility, we replicated the method of Study 1 with a broader sample.

\section{Study 2}

\section{Method}

Participants. We ran a power analysis using $\mathrm{G}^{*}$ Power with effect sizes obtained from Study 1 as our estimated effect size. This was assumed to be a conservative effect size estimate as we had little variability in IMS in Study 1. From this, we concluded that we would need 291 parents to detect an interaction of IMS and discrepancy magnitude. We thus recruited 300 parents and allowed parents who had begun the study to complete the study once we reached our target sample size.

Parents (224 females, 76 males, 1 did not identify) ranged in age from 22 to 64 years ( $M$ $=35.15$ years old). All parents had lived in the U.S. for at least 5 years, and did not have any Black or African American immediate family members. The sample was $85.71 \%$ White, 3.99\% Hispanic, $4.32 \%$ Asian, and $4.65 \%$ other races. The median household income of the sample was between $\$ 40,000$ and $\$ 50,000$ per year. Parents in this sample had the following highest degrees, showing greater variability than in the prior study: $14.29 \%$ had graduate degrees, $31.23 \%$ had bachelor's degrees, $24.58 \%$ had associate's degrees, and $29.57 \%$ had high school degrees.

Recruitment and Design. Parents participated through Amazon's Mechanical Turk online in exchange for $\$ 1$. Study 2 materials were identical to those in Study 1 with the exception of reducing the number of should and would items to 7 (See Appendix). As in Study 1, parents 
had at least one child between the ages of 4 and 12 and were randomly assigned to think about one of their children throughout the study $(M=7.38$ years, $S D=2.71$ years $)$.

\section{Results}

Overview of Analyses. The hypotheses and analysis plan for Study 2 were preregistered on the Open Science Framework. As in Study 1, negative discrepancy scores $(n=48)$ were excluded from analyses involving discrepancy scores. Descriptive statistics from Study 2 can be seen in Table 4. The distributions for each of the variables were similar to those from Study 1.

Shoulds and Woulds for Children's Behavior. Supporting Hypothesis 1 and replicating the results of Study 1, as parents increased in IMS, they reported that their children should express less bias, $B=-0.29, S E=0.02, t(298)=-12.09, p<0.001, \Delta R^{2}=0.33$. We also replicated the inverse relation between IMS and parents' ratings for how their children would behave in race-related situations, $B=-0.23, S E=0.03, t(298)=-8.54, p<0.001, \Delta R^{2}=0.20$.

Affect Analyses. We followed the same analytic strategy used in Study 1. See Table 5 for the summary of all effects in the full regression models. As in Study 1, parents who were higher in IMS reported less negative self-directed affect $(p=0.002)$. Additionally, as discrepancies increased, parents reported more negative self-directed affect $(p=.001)$, and as children's age increased, parents reported less negative self-directed affect $(p=0.03)$. Consistent with Hypothesis 2, there was a significant IMS by discrepancy magnitude interaction for negative self-directed affect $(p=0.03)$. Simple slope analyses revealed that participants who were high in IMS expressed more negative self-directed affect as discrepancies increased $(B=$ $\left..92, t(250)=3.58, p<.001, \Delta R^{2}=.05\right)$. In contrast, there was no effect of discrepancies on negative self-directed affect for participants low in IMS $\left(B=.20, t(250)=.85, p=.39, \Delta R^{2}=\right.$ $.003)$. Parents who were higher in IMS also reported more positive affect $(p=0.002)$, and discrepancy magnitude negatively predicted positive affect $(p=.003)$. 
There was also a main effect of IMS on negative child-directed affect $(p=0.004)$ such that as parents increased in IMS, they decreased in negative child-directed affect. Additionally, as discrepancies increased, parents reported more negative child-directed affect $(p<.001)$ and as child age increased, parents reported less negative child-directed affect $(p=.03)$. The main effect of IMS was qualified by a significant IMS by discrepancy magnitude interaction on negative child-directed affect $(p=0.02)$. The interaction was not moderated by child age $(p=0.84)$, failing to support Hypothesis 3. As with negative self-directed affect, simple slope analyses revealed that the interactive effect of IMS and discrepancy magnitude was primarily driven by elevated negative child-directed affect as discrepancies increased for participants high in IMS ( $B$ $\left.=.99, t(250)=4.60, p<.001, \Delta R^{2}=.07\right)$. Low IMS participants showed a marginal increase in negative child-directed affect as discrepancies increased $\left(B=.34, t(250)=1.74, p=.08, \Delta R^{2}=\right.$ $.01)$.

\section{Discussion}

Study 2 revealed some clear consistencies with Study 1 as well as some notable differences. As in Study 1, parents' values strongly predicted their standards for children's acceptable behavior in the race domain and parents who were higher in IMS expected their children would express less bias than did their low IMS counterparts. Additionally, as in Study 1, parents expected a smaller magnitude of violations of their standards by their children than adults anticipate from themselves (Plant \& Devine, 1998).

In contrast to Study 1, but supporting Hypothesis 2, IMS and discrepancy magnitude interacted to predict negative self-directed affect. This finding replicates the pattern observed in the extant literature showing that high but not low IMS adults express negative self-directed affect in response to personal violations of their standards (e.g., Plant \& Devine, 1998). By extending the paradigm to the parent/child dyad, Study 2 shows that high IMS parents hold 
themselves accountable for children's biased transgressions to a greater degree than low IMS parents. The present study also showed that high but not low IMS parents reported negative child-directed affect when they anticipated their children's behavior to violate their standards.

The samples for Study 1 and Study 2 were comparable on the overall descriptive statistics and the relation between IMS and parents' reports of the should and would responses. As such, we do not believe the samples differ in systematic ways but rather that the larger sample in Study 2 simply afforded the opportunity to detect predicted effects even with a small overall magnitude of discrepancies. Hence, we anticipated that if Study 1 parents were to consider a situation in which their child behaved in an unambiguously biased way, high IMS participants would report elevated negative self-directed affect whereas their low IMS counterparts would not (Hypothesis 2). Further, given that parents see older children as more intentional actors (Dix et al., 1986), we anticipated that high IMS but not low IMS parents may respond with elevated levels of negative child-directed affect as children aged (Hypothesis 3).

\section{Study 3}

To test these possibilities, in Study 3, we recruited a subset of the parents from Study 1 and asked them to vividly imagine their child expressing a specific, overt racially biased behavior and then report their affect. Such an approach has been used effectively in the adult literature on prejudice and self-regulation (Crisp, Birtel, \& Meleady, 2011; Devine et al., 1991; Plant \& Devine, 1998). That is, imagining failures to respond consistently with important nonprejudiced standards leads to the same affective and self-regulatory outcomes as reacting to actual failures (Devine \& Monteith, 1993; Monteith, 1993). This alternative paradigm controls for the particular behaviors that parents are imagining such that all parents consider the same behaviors in which bias is present and cannot plausibly be denied. This approach affords the opportunity to directly compare parents' responses in Studies 1 and 3 to evaluate how parents 
react when expecting their children to behave in line with their standards (Study 1) versus when imagining their child clearly engaging in a racially biased behavior (Study 3).

\section{Method}

Participants. Parents who participated in Study 1 and indicated a desire to be contacted about future research opportunities for their family (69\% of Study 1 sample) were asked to complete this follow-up study. Of the parents we contacted, 94\% $(N=142)$ completed Study 3.

Recruitment and Design. Study 3 began 2 months after the completion of Study 1. Parents completed Study 3 online on their own computers. Parents received a $\$ 5$ gift card.

Materials and Procedure. Parents were randomly presented with one of four vignettes. The vignettes were situations in which a child overtly expressed racial bias; the vignettes were varied in a couple ways, such as whether the race-related incident occurred at home or in public and whether the behaviors derogated an outgroup or favored an ingroup member, to ensure that responses were not unique to a particular context. These variations in the vignettes did not alter parents' responses and will not be discussed further. Parents were asked to imagine the situation presented in the vignette as vividly as possible and to imagine how they would feel or what they might do in the situation. Parents were assigned to think of the same child between ages 4 and 12 that they reported on in Study 1 and the child age and gender was input into the vignettes $(M=$ $6.87, S D=2.23)$. An example of a vignette was:

Imagine that you are talking with your [10-year-old boy] as [he] is getting ready for bed about who [he] would like to invite to an end of the year party at your house. You are reading aloud a list of the kids in your child's class and your child has said yes to inviting all of their classmates except for one, Malik. When you ask why your child does not want to invite Malik, [he] says "Because I don't like Black kids."

The remaining vignettes can be found in the Supplemental Materials. 
Affect measure. Parents completed the affect measure used in Study 1. This time, however, they were asked to report how they would feel if the presented scenario actually occurred. Parents were also asked an open-ended question about how they would react to the scenarios. Open-ended responses were widely variable, leading to low percentages of any given coded response. Thus, open-ended responses will not be discussed further but are available on

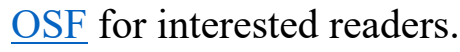

\section{Results}

Affect Analyses. As for Studies 1 and 2, we regressed negative self-directed affect, negative child-directed affect, and positive affect, in turn, on IMS, child age, and their interaction. Results corresponding to each relevant hypothesis and other significant effects are reported below. See Table 6 for the summary of all effects in the full regression models. In support of Hypothesis 2, parents who were higher in IMS responded to racially biased incidents with more negative self-directed affect $(p=0.04)$. Further, as parents increased in IMS, they reported less positive affect $(p=0.006)$. Parents expressed more negative child-directed affect with increases in child age $(p=0.04)$, but there were no significant interactions between IMS and child age $(p \mathrm{~s}>0.45)$, failing to support Hypothesis 3. These findings suggest that parents hold their children increasingly accountable with age regardless of parents' level of IMS.

Because the parents in Study 3 were a large subset of the parents from Study 1, we had an opportunity to compare the same parents' affective reactions across the studies. In Study 1, children's behavior was generally consistent with their parents' standards, and in Study 3 children's behavior transgressed the parents' standards (Study 3). Thus, for these analyses, we considered Study 1 as a "biased behavior absent" condition and Study 3 a "biased behavior present" condition. In support of this characterization of the studies, we observed that overall, 
parents felt more negative self-directed affect, more negative child-directed affect, and less positive affect in Study 3 than in Study 1, $p$ s $<0.001$ (see Table 7).

Next, as the primary hypothesis test, we assessed the effect of "condition" on parents' affective reactions by calculating the difference between affect scores in Studies 1 and 3 for each participant and then regressing the difference score on IMS, child age, and their interaction (see Table 8 for a summary of regression analyses). Following the predicted pattern, parents reported more negative self-directed affect as a function of IMS when biased behavior was present (Study 3) versus absent (Study 1), consistent with Hypothesis $2(p<0.001)$. Supporting the proposition that positive affect should be inversely related to negative affect, parents expressed less positive affect as a function of IMS in the biased behavior present than absent condition $(p<0.001)$. Parents also reported more negative child-directed affect when a biased behavior was present than absent as they increased in IMS $(p=.05)$, and as children aged (see Figure $1 ; p=.008$ ).

\section{Discussion}

In Study 3, we examined parents' affective responses to a specific instance in which they imagined their child responding with racial bias. Conceptually replicating Study 2, parents reported more negative self-directed affect in response to children's biased behavior as they increased in IMS. Once again, high IMS parents viewed children's transgressions as a personal failure. In contrast to Study 2, parents reported more negative child-directed affect as children aged, regardless of their level of IMS, suggesting that all parents held children responsible for their behaviors as they aged.

Study 3 in conjunction with Study 1 afforded the opportunity to conceptually replicate Study 2 to evaluate how parents respond in the presence versus absence of a biased transgression. Across the studies, our findings provide evidence that parents report very little affective distress in the absence of a transgression of their standards and their level of distress 
absent discrepancies does not vary as a function of IMS. However, when their child's behavior overtly violated parents' standards, parents reported more negative self-directed affect as they increased in IMS. Consistent with Study 2 and providing further support for Hypothesis 2, Study 3 demonstrates that parents who have deeply internalized values prohibiting prejudice primarily experience negative affect directed at the self when their children violate their standards.

\section{General Discussion}

In the present research, we evaluated parents' standards for their children's race-related behaviors and affective reactions to children's violations of parents' standards. To do this, we applied the Values Framework (e.g., Devine et al., 1991; Plant \& Devine, 1998) to the novel context of the parent-child dyad. Across the studies, we found that the standards parents set for their children in the race domain vary as a function of their level of internal motivation to respond without prejudice (Studies 1 and 2). Furthermore, imagining children's biased transgressions led high but not low IMS parents to report negative self-directed affect (Studies 2 and 3) suggesting that high IMS parents hold themselves personally accountable for their children's racially biased transgressions. This pattern of findings provides a replication of patterns reported by Devine and colleagues in the context of personal violations of self-imposed standards (Devine et al., 1991; Plant \& Devine, 1998).

Given the mixed effects for Hypothesis 3 across studies, we cannot make strong claims about the effect of child age on parents' affective reactions to violations of their standards. One possibility is that our hypothesis was incorrect - namely, high IMS parents may not feel more negative child-directed affect in response to violations of their standards as their children get older. Another possibility is that we did not capture the correct age range to detect age effects because the children were all in early- to middle-childhood. Twelve years of age is recognized as a transitional age between childhood and adolescence. It may then (rather than within the age 
range we studied) that parents' reactions to children begin to change as children become increasingly responsible for their own behaviors (Collins, 1990).

Taken together, the present research contributes a deeper understanding of topics relevant to both the social psychological adult literature, and the developmental child literature. In particular, parents' reports of negative self-directed affect hold great potential for the regulation of children's biases. Prior research has shown that negative self-directed affect can motivate people to reduce personal transgressions of their standards (e.g., Amodio et al., 2007; Monteith et al., 2002). To the extent that parents' behaviors resemble those in previous research, as parents become aware of children's biases that are in excess of parental standards, they should be motivated to engage in regulatory efforts to realign children's behaviors with parents' standards. Thus, it may be possible to leverage parents' reactions to engage parents in efforts to reduce children's biases before they are deeply entrenched (Rutland \& Killen, 2015).

Parents are in a unique circumstance for fostering behavioral change in children as they have extensive and continued contact with their children, have situational power over children, have opportunities to guide children's behaviors, and have a responsibility to teach their children acceptable behavior. Thus, if parents are motivated to engage in regulatory efforts to align their children's behaviors with their standards, engaging parents in intervention efforts may serve as a powerful tool for enacting widespread change. Whereas adults have the requisite self-regulatory abilities to sustain their own prejudice reduction efforts, children's executive functioning is limited (Best \& Miller, 2010). Involving parents in intervention efforts for children provides the opportunity for parents to scaffold interventions that have been tested in the lab (e.g., intergroup contact; Lemmer \& Wagner, 2015) in a broader context. If properly motivated, parents have the cognitive skills to continually implement intervention efforts in a long-term attempt to reduce children's biases. Future research should focus on the evaluation of parents as interventionists 
and evaluate the longitudinal effects of interventions implemented on a larger scale than traditional laboratory interventions. As suggested by Skinner and Meltzoff (in press), the particular types of intervention strategies implemented should be tailored to the developmental level and capacities of the child.

The present studies suggest that high IMS parents experience negative self-directed affect and would likely engage in regulatory efforts to correct their children's behavior when their children express bias, even when discrepancies are relatively small. Yet, prior literature suggests that children express racial biases more akin to those presented in Study 3 - behaviors that would be characterized by many parents as a large discrepancy from their standards (Aboud, 1988; Brown \& Bigler, 2005; Simons et al., 2002). Why might parents' predictions for their children's behaviors differ from their children's actual behaviors? It is possible that parents do not typically witness their children's expressions of bias. Parents do not observe their children in all circumstances (e.g., at school, on the playground) and, hence, may miss instances in which their children express bias. When with their parents, children may be on their best behavior and may not display the degree of bias they express in other situations. Thus, what parents are reporting according to their own understanding may actually be true. Alternatively, parents could fall prey to a form of the better-than-average effect in which they think their children are less likely than other children to express bias (Alicke, 1985; Brown, 1986). Our data cannot distinguish these explanations for why many parents report small discrepancies; future work should evaluate this question to understand how parents will handle circumstances in which children engage in behaviors that are seen as both small and large violations of parents' standards.

\section{Limitations and Future Directions}

The present approach holds great promise for understanding the way that parents think about, react to, and may influence their children's biases. There are, however, limitations of the 
studies that should be addressed in future research. First, the situations presented in the present study did not systematically vary the severity of children's biases. How might parents respond to more subtle instances of racial bias? Would parents who are high in IMS feel negative selfdirected affect if children, for example, chose to give more stickers to White than to Black classmates? Although the present studies did not reveal statistical differences among scenarios, future research should systematically evaluate the extent to which the severity and nature of children's biases influence parental reactions. Moreover, how would parents respond to biases related to gender, a domain in which transgressions are typically viewed as less egregious (Czopp \& Monteith, 2003)?

Furthermore, despite efforts to expand the sample in Study 2, the parents in all three studies were relatively high in IMS. Although we find the predicted patterns of results based on IMS across the studies, it remains unclear how parents who are truly low in IMS would set standards for their children or would respond to children's biased behaviors. Future research should evaluate individuals who are not motivated to respond without prejudice, or who are motivated to respond with prejudice (Forscher, Cox, Graetz, \& Devine, 2015). Finally, our sample consisted primarily of White parents who may be especially unaware of children's racial biases as they do not experience prejudice against their own group on the basis of race. Future research should evaluate how parents of different races react to children's biases. It will be important to carefully evaluate the generalizability of the present findings before applying them more broadly.

\section{Conclusion}

The present research provides significant advances for considering parents' interpretations of children's racial bias and parents' potential for addressing children's biases. By establishing a foundation for understanding how parents may influence children's developing 
racial biases, we can begin to examine dyadic questions on parental regulation of children's biases and the influence of parental reactions to children's biases on children's racial attitude development. Understanding parental reactions to imagining children's biases provides critical information on how to approach future research and intervention efforts with parents and children in this domain. This research provides groundwork for examining questions about the relationship between parents and children in the race domain, parental regulation of children's biases, and the potential leverage the parent-child relationship may provide for reducing racial bias across the lifespan. 


\section{References}

Aboud, F. (1988). Children and prejudice. Cambridge, MA: Basil Blackwell.

Aboud, F., \& Skerry, S. A. (1984). The development of ethnic attitudes: A critical review. Journal of Cross-Cultural Psychology, 15, 3-34. https://doi.org/10.1177/0022002184015001001

Allport, G. W. (1954). The nature of prejudice. Oxford, England: Addison-Wesley.

Alicke, M. D. (1985). Global self-evaluation as determined by the desirability and controllability of trait adjectives. Journal of Personality and Social Psychology, 49, 1621-1630.

\section{http://dx.doi.org/10.1037/0022-3514.49.6.1621}

Amodio, D. M., Devine, P. G., \& Harmon-Jones, E. (2007). A dynamic model of guilt: Implications for motivation and self-regulation in the context of prejudice. Psychological Science, 18, 524-530. https://doi.org/10.1111/j.1467-9280.2007.01933.x

Baron, A. S., \& Banaji, M. R. (2006). The development of implicit attitudes: Evidence of race evaluations from age 6, 10, and adulthood. Psychological Science, 17, 53-58. https://doi.org/10.1111/j.1467-9280.2005.01664.x

Best, J. R., \& Miller, P. H. (2010). A developmental perspective on executive function. Child Development, 81, 1641-1660. https://doi.org/10.1111/j.1467-8624.2010.01499.x

Brown, C. S., \& Bigler, R. S. (2005). Children's perceptions of discrimination: A developmental model. Child Development, 76, 533-553. http://www.jstor.org/stable/3696450

Collins, W. A., (1990). Parent-child relationships in the transition to adolescence: Continuity and change in interaction, affect, and cognition. In R. Montemayor, G. R., Adams, \& T. P. Gullotta (Eds.), Advances in adolescent development: An annual book series, Vol. 2. From childhood to adolescence: A transitional period? (pp. 85-106). Thousand Oaks, CA, US: Sage Publications, Inc. 
Crisp, R. J., Birtel, M. D., \& Meleady, R. (2011). Mental simulations of social thought and action: Trivial tasks or tools for transforming social policy? Current Directions in Psychological Science, 20, 261-264. https://doi.org/10.1177/0963721411413762

Czopp, A. M., \& Monteith, M. J. (2003). Confronting prejudice (literally): Reactions to confrontations of racial and gender bias. Personality and Social Psychology, 29, 532-544. https://doi.org/10.1177/0146167202250923

Devine, P. G., Monteith, M. J., Zuwerink, J. R., \& Elliot, A. J. (1991). Prejudice with and without compunction. Journal of Personality and Social Psychology, 60, 817-830.

\section{http://dx.doi.org/10.1037/0022-3514.60.6.817}

Dix, T., Ruble, D. N., Grusec, J. E., \& Nixon, S. (1986). Social cognition in parents: Inferential and affective reactions to children of three age levels. Child Development, 57, 879-894. https://doi.org/10.2307/1130365

Dunham, Y., Baron, A. S., \& Banaji, M. R. (2007). Children and social groups: A developmental analysis of implicit consistency in Hispanic Americans. Self and Identity, 6, 238-255. https://doi.org/10.1080/15298860601115344

Forscher, P. S., Cox, W. T. L., Graetz, N., \& Devine, P. G. (2015). The motivation to express prejudice. Journal of Personality and Social Psychology, 109, 791-812. http://dx.doi.org/10.1037/pspi0000030

Granqvist, P. (2002). Attachment and religiosity in adolescence: Cross-sectional and longitudinal evaluations. Personality and Social Psychology Bulletin, 28, 260-270. https://doi.org/10.1177/0146167202282011

Jennings, M. K., Stoker, L., \& Bowers, J. (2009). Politics across generations: Family transmission reexamined. The Journal of Politics, 71, 782-799. https://doi.org/10.1017/S0022381609090719 
Judd, C. M., McClelland, G. H., \& Ryan, C. S. (2011). Data analysis: A model comparison approach. New York, NY: Routledge.

Kowalski, K. (2003). The emergence of ethnic and racial attitudes in preschool-aged children. Journal of Social Psychology, 143, 677-690. https://doi.org/10.1080/00224540309600424

Leiderman, R. C. (2016). How should I react when my child hears someone make a racist remark? Baby Center. Retrieved from https://www.babycenter.com/404 how-should-ireact-when-my-child-hears-someone-make-a-racist 71735.bc

Lemmer, G., \& Wagner, U. (2015). Can we really reduce ethnic prejudice outside the lab? A meta-analysis of direct and indirect contact interventions. European Journal of Social Psychology, 45, 152-168. https://dx.doi.org/10.1002/ejsp.2079

Mitamura, C., Erickson, L., \& Devine, P. G. (2017). Value-based standards guide sexism inferences for self and others. Journal of Experimental Social Psychology, 72, 101-117. http://dx.doi.org/10.1016/j.jesp.2017.04.006

Monteith, M. J. (1993). Self-regulation of prejudiced responses: Implications for progress in prejudice-reduction efforts. Journal of Personality and Social Psychology, 65, 469-485. http://dx.doi.org/10.1037/0022-3514.65.3.469

Monteith, M. J., Ashburn-Nardo, L., Voils, C. I., \& Czopp, A. M. (2002). Putting the brakes on prejudice: On the development and operation of cues for control. Journal of Personality and Social Psychology, 83, 1029-1050. http://dx.doi.org/10.1037/0022-3514.83.5.1029

Newheiser, A. K., \& Olson, K. R. (2012). White and Black American children's implicit intergroup bias. Journal of Experimental Social Psychology, 48, 264-270. https://doi.org/10.1016/j.jesp.2011.08.011 
Pahlke, E., Bigler, R. S., \& Suizzo, M. A. (2012). Relations between colorblind socialization and children's racial bias: Evidence from European American mothers and their preschool children. Child Development, 83, 1164-1179. https://doi.org/10.1111/j.1467$\underline{8624.2012 .01770 . x}$

Pauker, K., Ambady, N., \& Apfelbaum, E. P. (2010). Race salience and essentialist thinking in racial stereotype development. Child Development, 81, 1799-1813. https://doi.org/10.1111/j.1467-8624.2010.01511.x

Plant, E. A., \& Devine, P. G. (1998). Internal and external motivation to respond without prejudice. Journal of Personality and Social Psychology, 75, 811-832.

\section{http://dx.doi.org/10.1037/0022-3514.75.3.811}

Raabe, T., \& Beelmann, A. (2011). Development of ethnic, racial, and national prejudice in childhood and adolescence: A multinational meta-analysis of age differences. Child Development, 82, 1715-1737. https://doi.org/10.1111/j.1467-8624.2011.01668.x

Renno, M. P., \& Shutts, K. (2015). Children's social category-based giving and its correlates: Expectations and preferences. Developmental Psychology, 51, 533-543. http://dx.doi.org/10.1037/a0038819

Rutland, A., \& Killen, M. (2015). A developmental science approach to reducing prejudice and social exclusion: Intergroup processes, social-cognitive development, and moral reasoning. Social Issues and Policy Review, 9, 121-154. https://doi.org/10.1111/sipr.12012

Simons, R., Murry, V., McLoyd, V., Lin, K., Cutrona, C., \& Conger, R. (2002). Discrimination, crime, ethnic identity, and parenting as correlates of depressive symptoms among African American children: A multilevel analysis. Development and Psychopathology, 14, 371393. https://doi.org/10.1017/S0954579402002109 
Skinner, A. L., \& Meltzoff, A. N. (in press). Childhood experiences and intergroup biases among children. Social Issues and Policy Review. https://doi.org/10.1111/sipr.12054

Smetana, J. G. (1999). The role of parents in moral development: A social domain analysis. Journal of Moral Education, 28, 311-321. https://doi.org/10.1080/030572499103106

Vittrup, B. (2016). Color blind or color conscious? White American mothers' approaches to racial socialization. Journal of Family Issues, 39, 668-692. https://doi.org/10.1177/0192513X16676858

Vittrup, B., \& Holden, G. W. (2010). Exploring the impact of educational television and parentchild discussions on children's racial attitudes. Analyses of Social Issues and Public Policy, 11, 82-104. https://doi.org/10.1111/j.1530-2415.2010.01223.x

Walker, L. J., \& Taylor, J. H. (1991). Family interactions and the development of moral reasoning. Child Development, 62, 264-283. https://doi.org/10.1111/j.1467$\underline{8624.1991 . t b 01530 . x}$

Waxman, S., Richeson, J., \& Rogers, L. O. (2017, January 19). Be 'color-brave' with your kids. U.S. News and World Report. Retrieved from https://www.usnews.com/opinion/oped/articles/2017-01-19/talk-honestly-with-children-about-race-in-the-donald-trump-era

Weisman, K., Johnson, M. V., \& Shutts, K. (2015). Young children's automatic encoding of social categories. Developmental Science, 18, 1036-1043. doi: 10.1111/desc.12269

Yoffe, E. (2013, February 7). Mommy's little bigot: My young daughter won't stop spouting racist comments. Slate. Retrieved from http://www.slate.com/articles/life/dear_prudence/2013/02/dear_prudence_my_little_girl_ might be racist how_do_i_stop_it.html 
Zucker, J. K., \& Patterson, M. M. (2018). Racial socialization practices among White American parents: Relations to racial attitudes, racial identity, and school diversity. Journal of Family Issues, 1-28. https://doi.org/10.1177/0192513X18800766 
Table 1

Study 1 Descriptive Statistics

\begin{tabular}{|c|c|c|c|c|c|c|}
\hline & Mean & SD & Min & $\operatorname{Max}$ & Alpha & Skew \\
\hline IMS & 6.17 & 0.83 & 2.00 & 7.00 & 0.78 & -1.32 \\
\hline Shoulds & 1.30 & 0.48 & 1.00 & 3.79 & 0.75 & 2.33 \\
\hline Woulds & 1.44 & 0.53 & 1.00 & 3.86 & 0.79 & 1.57 \\
\hline All Discrepancies & 0.14 & 0.50 & -2.07 & 1.93 & 0.59 & -0.27 \\
\hline $\begin{array}{l}\text { Non-Negative } \\
\text { Discrepancies }\end{array}$ & 0.29 & 0.38 & 0.00 & 1.93 & 0.43 & 1.77 \\
\hline $\begin{array}{l}\text { Negative Self-Directed } \\
\text { Affect }\end{array}$ & 1.78 & 1.06 & 1.00 & 5.80 & 0.97 & 1.64 \\
\hline $\begin{array}{l}\text { Negative Child- } \\
\text { Directed Affect }\end{array}$ & 1.51 & 0.97 & 1.00 & 6.17 & 0.95 & 2.31 \\
\hline Positive Affect & 5.38 & 1.36 & 1.00 & 7.00 & 0.90 & -0.97 \\
\hline Child Age (Years) & 6.88 & 2.27 & 4.00 & 12.00 & -- & 0.39 \\
\hline
\end{tabular}


Table 2

Study 1 Correlations Between Variables

\begin{tabular}{|c|c|c|c|c|c|c|c|}
\hline & IMS & Shoulds & Woulds & $\begin{array}{l}\text { Non-Negative } \\
\text { Discrepancies }\end{array}$ & $\begin{array}{l}\text { Negative Self- } \\
\text { Directed Affect }\end{array}$ & $\begin{array}{l}\text { Negative Child- } \\
\text { Directed Affect }\end{array}$ & $\begin{array}{c}\text { Positive } \\
\text { Affect }\end{array}$ \\
\hline \multicolumn{8}{|l|}{ IMS } \\
\hline Shoulds & $-0.41 * * *$ & & & & & & \\
\hline Woulds & $-0.43 * * *$ & $0.52 * * *$ & & & & & \\
\hline $\begin{array}{l}\text { Non-Negative } \\
\text { Discrepancies }\end{array}$ & $-0.17^{*}$ & 0.05 & $0.71 * * *$ & & & & \\
\hline $\begin{array}{l}\text { Negative Self- } \\
\text { Directed Affect }\end{array}$ & $-0.14^{*}$ & $0.21 * *$ & $0.32 * * *$ & $0.20 * *$ & & & \\
\hline $\begin{array}{l}\text { Negative Child- } \\
\text { Directed Affect }\end{array}$ & $-0.19 * *$ & $0.26 * * *$ & $0.30 * * *$ & 0.08 & $0.80 * * *$ & & \\
\hline Positive Affect & $0.26^{* * *}$ & $-0.13^{\dagger}$ & $-0.21 * * *$ & $-0.13^{\dagger}$ & $-0.35 * * *$ & $-0.24 * * *$ & \\
\hline $\begin{array}{l}\text { Child Age } \\
\text { (Years) }\end{array}$ & -0.02 & 0.03 & -0.04 & -0.07 & $-0.19 * *$ & -0.09 & 0.17 \\
\hline
\end{tabular}

Note. $N=219$. IMS = Internal Motivation to Respond Without Prejudice Scale. Non-Negative Discrepancies $=$ Discrepancies scores that are equal to or greater than $0 .{ }^{* * *} p<0.001,{ }^{* *} p<0.01,{ }^{*} p<0.05,{ }^{\dagger} p<0.10$ 
Table 3

Study 1 Regression Analyses on Affect Indices

\begin{tabular}{|c|c|c|c|c|c|}
\hline \multicolumn{6}{|l|}{ Negative Self-Directed Affect } \\
\hline & B & Std Er & $t$ & $p$ & $\Delta R^{2}$ \\
\hline IMS & -0.32 & 0.12 & -2.70 & $0.008 * *$ & 0.038 \\
\hline Discrepancies & 0.50 & 0.23 & 2.19 & $0.030 *$ & 0.025 \\
\hline Child Age & -0.10 & 0.04 & -2.56 & $0.011 *$ & 0.034 \\
\hline IMS X Discrepancies & 0.31 & 0.36 & 0.87 & 0.385 & 0.004 \\
\hline IMS X Child Age & 0.04 & 0.04 & 0.74 & 0.460 & 0.003 \\
\hline Discrepancies X Child Age & -0.01 & 0.10 & -0.12 & 0.904 & $<0.001$ \\
\hline IMS X Discrepancies X Child Age & -0.25 & 0.15 & -1.71 & $0.089^{\dagger}$ & 0.015 \\
\hline \multicolumn{6}{|l|}{ Negative Child-Directed Affect } \\
\hline & $\mathrm{B}$ & Std Er & $t$ & $p$ & $\Delta R^{2}$ \\
\hline IMS & -0.33 & 0.11 & -2.92 & $0.004 * *$ & 0.047 \\
\hline Discrepancies & 0.13 & 0.22 & 0.60 & 0.549 & 0.002 \\
\hline Child Age & -0.05 & 0.04 & -1.42 & 0.156 & 0.011 \\
\hline IMS X Discrepancies & 0.14 & 0.35 & 0.40 & 0.692 & $<0.001$ \\
\hline IMS X Child Age & -0.02 & 0.05 & -0.34 & 0.737 & $<0.001$ \\
\hline Discrepancies X Child Age & 0.03 & 0.10 & 0.33 & 0.743 & $<0.001$ \\
\hline IMS X Discrepancies X Child Age & -0.04 & 0.14 & -0.31 & 0.758 & $<0.001$ \\
\hline \multicolumn{6}{|l|}{ Positive Affect } \\
\hline & $\mathrm{B}$ & Std Er & $t$ & $p$ & $\Delta R^{2}$ \\
\hline IMS & 0.34 & 0.15 & 2.28 & $0.024 *$ & 0.029 \\
\hline Discrepancies & -0.32 & 0.29 & -1.12 & 0.267 & 0.007 \\
\hline Child Age & 0.08 & 0.05 & 1.68 & $0.095^{\dagger}$ & 0.016 \\
\hline IMS X Discrepancies & 0.05 & 0.45 & 0.10 & 0.918 & $<0.001$ \\
\hline IMS X Child Age & 0.06 & 0.06 & 0.91 & 0.363 & 0.005 \\
\hline Discrepancies X Child Age & -0.04 & 0.13 & -0.35 & 0.728 & $<0.001$ \\
\hline IMS X Discrepancies X Child Age & -0.13 & 0.18 & -0.71 & 0.480 & 0.003 \\
\hline
\end{tabular}

Note. $d f=215$. Predictor variables are centered around the mean. IMS $=$ Internal Motivation to Respond Without Prejudice Scale. Discrepancies $=$ Woulds - Shoulds. ${ }^{* * *} p<0.001,{ }^{*} p<0.01$, ${ }^{*} p<0.05,{ }^{\dagger} p<0.10$ 
Table 4

Study 2 Descriptive Statistics

\begin{tabular}{|c|c|c|c|c|c|c|}
\hline & Mean & SD & Min & Max & Alpha & Skew \\
\hline IMS & 5.94 & 1.28 & 1.00 & 7.00 & 0.87 & -1.61 \\
\hline Shoulds & 1.31 & 0.63 & 1.00 & 5.57 & 0.80 & 3.11 \\
\hline Woulds & 1.43 & 0.65 & 1.00 & 5.00 & 0.73 & 2.24 \\
\hline All Discrepancies & 0.12 & 0.51 & -1.57 & 3.29 & 0.39 & 0.99 \\
\hline $\begin{array}{l}\text { Non-Negative } \\
\text { Discrepancies }\end{array}$ & 0.25 & 0.43 & 0.00 & 3.29 & 0.31 & 2.65 \\
\hline $\begin{array}{l}\text { Negative Self-Directed } \\
\text { Affect }\end{array}$ & 1.86 & 1.17 & 1.00 & 6.55 & 0.97 & 1.61 \\
\hline $\begin{array}{l}\text { Negative Child- } \\
\text { Directed Affect }\end{array}$ & 1.51 & 1.01 & 1.00 & 6.67 & 0.94 & 2.63 \\
\hline Positive Affect & 5.40 & 1.39 & 1.00 & 7.00 & 0.90 & -1.12 \\
\hline Child Age (Years) & 7.38 & 2.71 & 4.00 & 12.00 & -- & 0.28 \\
\hline
\end{tabular}


Table 5

Study 2 Regression Analyses on Affect Indices

\begin{tabular}{|c|c|c|c|c|c|}
\hline \multicolumn{6}{|l|}{ Negative Self-Directed Affect } \\
\hline & $\mathrm{B}$ & Std Er & $t$ & $p$ & $\Delta R^{2}$ \\
\hline IMS & -0.23 & 0.07 & -3.17 & $0.002 * *$ & 0.036 \\
\hline Discrepancies & 0.58 & 0.18 & 3.27 & $0.001 * *$ & 0.038 \\
\hline Child Age & -0.06 & 0.03 & -2.21 & $0.028^{*}$ & 0.018 \\
\hline IMS X Discrepancies & 0.35 & 0.16 & 2.13 & $0.034 *$ & 0.016 \\
\hline IMS X Child Age & 0.01 & 0.03 & 0.27 & 0.785 & $<0.001$ \\
\hline Discrepancies X Child Age & -0.10 & 0.07 & -1.50 & 0.134 & 0.008 \\
\hline IMS X Discrepancies X Child Age & -0.01 & 0.05 & -0.18 & 0.854 & $<0.001$ \\
\hline \multicolumn{6}{|l|}{ Negative Child-Directed Affect } \\
\hline & B & Std Er & $t$ & $p$ & $\Delta R^{2}$ \\
\hline IMS & -0.18 & 0.06 & -2.94 & $0.004 * *$ & 0.030 \\
\hline Discrepancies & 0.62 & 0.15 & 4.20 & $<0.001 * * *$ & 0.062 \\
\hline Child Age & -0.05 & 0.02 & -2.22 & $0.028^{*}$ & 0.017 \\
\hline IMS X Discrepancies & 0.31 & 0.14 & 2.28 & $0.023^{*}$ & 0.018 \\
\hline IMS X Child Age & 0.01 & 0.02 & 0.64 & 0.522 & 0.001 \\
\hline Discrepancies X Child Age & -0.01 & 0.06 & -0.26 & 0.798 & $<0.001$ \\
\hline IMS X Discrepancies X Child Age & -0.01 & 0.04 & -0.20 & 0.840 & $<0.001$ \\
\hline \multicolumn{6}{|l|}{ Positive Affect } \\
\hline & $\mathrm{B}$ & Std Er & $t$ & $p$ & $\Delta R^{2}$ \\
\hline IMS & 0.27 & 0.08 & 3.19 & $0.002 * *$ & 0.037 \\
\hline Discrepancies & -0.61 & 0.21 & -2.98 & $0.003 * *$ & 0.033 \\
\hline Child Age & 0.05 & 0.03 & 1.62 & 0.106 & 0.010 \\
\hline IMS X Discrepancies & 0.02 & 0.19 & 0.09 & 0.932 & $<0.001$ \\
\hline IMS X Child Age & -0.002 & 0.03 & -0.08 & 0.937 & $<0.001$ \\
\hline Discrepancies X Child Age & 0.06 & 0.08 & 0.76 & 0.450 & 0.002 \\
\hline IMS X Discrepancies X Child Age & 0.005 & 0.06 & 0.08 & 0.940 & $<0.001$ \\
\hline
\end{tabular}

Note. $d f=246$. Predictor variables are centered around the mean. IMS = Internal Motivation to Respond Without Prejudice Scale. Discrepancies $=$ Woulds - Shoulds. $* * * p<0.001, * * p<0.01$, ${ }^{*} p<0.05,{ }^{\dagger} p<0.10$ 
Table 6

Study 3 Affect Analyses

\begin{tabular}{|c|c|c|c|c|c|}
\hline \multicolumn{6}{|c|}{ Negative Self-Directed Affect } \\
\hline & $\mathrm{B}$ & Std Er & $t$ & $p$ & $\Delta R^{2}$ \\
\hline IMS & 0.31 & 0.15 & 2.07 & $0.040 *$ & 0.030 \\
\hline Child Age & -0.08 & 0.05 & -1.51 & 0.133 & 0.016 \\
\hline IMS X Child Age & -0.04 & 0.06 & -0.63 & 0.533 & 0.003 \\
\hline \multicolumn{6}{|c|}{ Negative Child-Directed Affect } \\
\hline & B & Std Er & $t$ & $p$ & $\Delta R^{2}$ \\
\hline IMS & 0.14 & 0.18 & 0.75 & 0.454 & 0.004 \\
\hline Child Age & 0.13 & 0.06 & 2.08 & $0.039 *$ & 0.031 \\
\hline IMS X Child Age & 0.03 & 0.07 & 0.48 & 0.632 & 0.002 \\
\hline \multicolumn{6}{|l|}{ Positive Affect } \\
\hline & $\mathrm{B}$ & Std Er & $t$ & $p$ & $\Delta R^{2}$ \\
\hline IMS & -0.20 & 0.07 & -2.82 & $0.006^{* *}$ & 0.053 \\
\hline Child Age & 0.02 & 0.02 & 0.82 & 0.414 & 0.005 \\
\hline IMS X Child Age & -0.02 & 0.03 & -0.70 & 0.483 & 0.003 \\
\hline
\end{tabular}

Note. $d f=137$. IMS $=$ Internal Motivation to Respond Without Prejudice Scale. ${ }^{* * *} p<0.001$, $*^{*} p<0.01,{ }^{*} p<0.05,{ }^{\dagger} p<0.10$

Table 7

Means and Standard Deviations for Affect in Study 1 vs. Study 3

\begin{tabular}{lcccc}
\hline & \multicolumn{2}{c}{ Study 1} & \multicolumn{2}{c}{ Study 3} \\
\hline & Mean & $S D$ & Mean & $S D$ \\
\hline Negative Self-Directed Affect & 1.72 & 1.00 & 3.60 & 1.40 \\
Negative Child-Directed Affect & 1.47 & 0.95 & 3.54 & 1.69 \\
Positive Affect & 5.54 & 1.33 & 1.31 & 0.67 \\
\hline
\end{tabular}

Note. $N=140$. Means and standard deviations for each study were calculated using only parents who participated in both Studies 1 and 3. 
Table 8

Study 1 vs. 3 Affect Analyses

\begin{tabular}{|c|c|c|c|c|c|}
\hline \multicolumn{6}{|c|}{ Negative Self-Directed Affect } \\
\hline & B & Std Er & $t$ & $p$ & $\Delta R^{2}$ \\
\hline IMS & 0.68 & 0.16 & 4.30 & $<0.001 * * *$ & 0.119 \\
\hline Child Age & 0.03 & 0.06 & 0.54 & 0.592 & 0.002 \\
\hline IMS X Child Age & -0.09 & 0.06 & -1.46 & 0.146 & 0.014 \\
\hline \multicolumn{6}{|c|}{ Negative Child-Directed Affect } \\
\hline & B & Std Er & $t$ & $p$ & $\Delta R^{2}$ \\
\hline IMS & 0.41 & 0.20 & 2.02 & $0.045^{*}$ & 0.028 \\
\hline Child Age & 0.19 & 0.07 & 2.71 & $0.008 * *$ & 0.050 \\
\hline IMS X Child Age & -0.002 & 0.08 & -0.02 & 0.982 & $<0.001$ \\
\hline \multicolumn{6}{|l|}{ Positive Affect } \\
\hline & $\mathrm{B}$ & Std Er & $t$ & $p$ & $\Delta R^{2}$ \\
\hline IMS & -0.71 & 0.14 & -4.84 & $<0.001 * * *$ & 0.139 \\
\hline Child Age & -0.10 & 0.05 & -1.93 & $0.056^{\dagger}$ & 0.022 \\
\hline IMS X Child Age & -0.04 & 0.06 & -0.70 & 0.487 & 0.003 \\
\hline
\end{tabular}

Note. $d f=137$. IMS $=$ Internal Motivation to Respond Without Prejudice Scale. A significant $\mathrm{p}-$ value represents a significant interaction between the predictor variable and the biased behavior absent/present condition (Study 1 or Study 3). ${ }^{* * *} p<0.001,{ }^{*} p<0.01,{ }^{*} p<0.05,{ }^{\dagger} p<0.10$ 

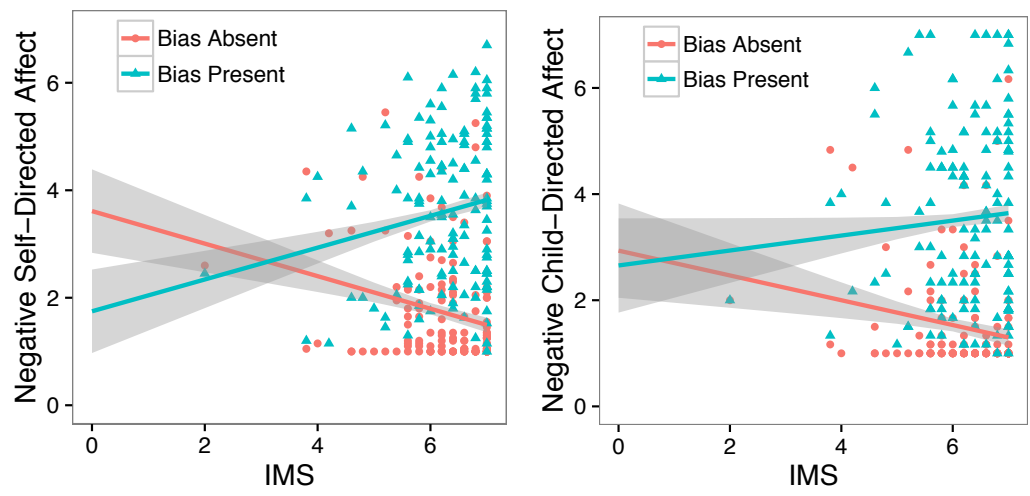

Figure 1. Interaction of IMS with bias condition on negative self-directed affect (left) and negative child-directed affect (right). Bias Absent $=$ Study 1; Bias Present $=$ Study 3. 
Appendix

\section{Shoulds Items (Studies 1 \& 2)}

Instructions: Parents often set up rules or standards for how their children should behave. The following questionnaire has to do with your child's interactions with people of different races. We are trying to understand how you think your child should behave in different situations. Please read each situation, and then indicate the degree to which you agree or disagree using the 1 (strongly disagree) to 7 (strongly agree) scale.

We recognize that asking questions about social groups can be sensitive. We want to emphasize that we are not trying to evaluate you or your child, but are rather trying to understand how parents generally think about these issues. Your responses will be averaged with other parents' responses and you can be sure that your responses will be kept confidential. We would also like to emphasize that there are no right or wrong answers. For us to learn anything useful, it is important that you be as honest and open as possible.

*Items were used in Study 1 and Study 2

**Items were used in just Study 1

***Items were used in just Study 2

*Your child should exclude another child from a play date because he/she is Black.

*Your child should let a Black child sit at the lunch table with him/her.

*Your child should not say "Black people are dumb."

*Your child should not think that White people are better than Black people.

* Your child should not use racial slurs.

** Your child should be afraid when a Black person walks by them on the street.

**Your child should not say "Black people are dirty."

**Your child should refuse to watch a TV show because the main character is Black.

**Your child should refuse to sit next to a Black person on the school bus.

**Your child should only want to play with White children.

**Your child should not tell a Black child "I don't like your brown skin."

**Your child should think a restaurant is bad because the waiter is Black.

**Your child should be scared about having a Black teacher.

**Your child should not think Black people are lazy.

***Your child should not play with Black children.

***Your child should not tell a Black child "your Brown skin is ugly."

\section{Woulds Items (Studies 1 \& 2)}

Instructions: Although parents have ideas about how their children should behave in social settings, sometimes their children's behavior is consistent with these ideas and sometimes their behavior is inconsistent with how parents think they should behave. In what follows, we present each of the situations you responded to previously. Please read each item and report how likely your child would be to actually respond as described using the 1 (strongly disagree) to 7 (strongly agree) scale. 
As before, we want to emphasize that there are no right or wrong answers. Your responses may or may not be consistent with the ones you gave earlier.

*Items were used in Study 1 and Study 2

** Items were used in just Study 1

*** Items were used in just Study 2

*Your child would exclude another child from a play date because he/she is Black.

*Your child would let a Black child sit at the lunch table with him/her.

*Your child would not say "Black people are dumb."

*Your child would not think that White people are better than Black people.

*Your child would not use racial slurs.

**Your child would be afraid when a Black person walks by them on the street.

**Your child would not say "Black people are dirty."

**Your child would refuse to watch a TV show because the main character is Black.

**Your child would refuse to sit next to a Black person on the school bus.

**Your child would only want to play with White children.

**Your child would not tell a Black child "I don't like your brown skin."

**Your child would think a restaurant is bad because the waiter is Black.

**Your child would be scared about having a Black teacher.

**Your child would not think Black people are lazy.

***Your child would not play with Black children.

***Your child would not tell a Black child "your Brown skin is ugly." 